Int. J. Electrochem. Sci., 15 (2020) 12281 - 12290

Short Communication

\title{
Calcined Clay and Limestone as Partial Replacements of Portland Cement: Electrochemical Corrosion Behavior of Low Carbon Steel Rebar as Concrete Reinforcement in Corrosive Environment
}

\author{
Fengren Guo* \\ Fujian Polytechnic of Information Technology, Department of Architectural Engineering, Fujian \\ Fuzhou, 350003, China \\ *E-mail: gfr219@126.com
}

doi: $10.20964 / 2020.12 .27$

Received: 1 August 2020 / Accepted: 22 September 2020 / Published: 31 October 2020

\begin{abstract}
Recent studies indicate that corrosion resistance of reinforced concrete could be improved by enhancing the concrete structure, particularly Portland cement (PC) replacement by mineral compounds. In this study, the effect of calcined clay (CC) and limestone (LS) as partial replacement of PC on corrosion resistance of HRB500 carbon steel reinforced concrete in $3.5 \% \mathrm{NaCl}$ solution were considered. After curing for one day, the PC replaced with both CC and LS admixtures revealed the strength of $28 \mathrm{MPa}$ while the mixture with only limestone showed a compressive strength of $21 \mathrm{MPa}$. The lower strength in blended concretes than the PC mixture can be attributed to the effect of cement dilution. Water absorption results indicate that transport of chloride ions, liquid and moisture is greatly reduced, mostly due to the pore structure refinement of the concrete sample with LS and CC admixtures. The polarization results reveal that the concrete specimens containing CC and LS admixtures had a lower corrosion value on the surface of carbon steel compared to the other specimens. The EIS findings exhibited that the double-layer capacitance value reduced for the concrete sample including both LS and CC admixtures, showing the passive layer thickness was enhanced and resulting in an improved protective capacity.
\end{abstract}

Keywords: Calcined clay and limestone admixtures; Electrochemical corrosion behavior; carbon steel rebar; Portland cement

\section{$\underline{\text { FULL TEXT }}$}

(C) 2020 The Authors. Published by ESG (www.electrochemsci.org). This article is an open access article distributed under the terms and conditions of the Creative Commons Attribution license (http://creativecommons.org/licenses/by/4.0/). 